\title{
Gender Impact on Mental Health and its Psychological Factors
}

\author{
V. Suriyakumar \\ PhD Research Scholar, Meston College of Education (Autonomous), Royapettah, Chennai-600014, TamilNadu, India
}

\begin{abstract}
The study aims to determine the factors involved in mental health based on gender impact on mental health and its psychological factors. Stratified random sampling technique was used for the selection of the sample. From the total population of 750 , 38 school students were selected from three different schools in Chennai city. Personal data sheet developed by the investigator, 'Family Factor scale' was prepared and validated by Dr.(Mrs) K. Saraladevi and Dr.(Mrs) Angela Selvarani (2006), Loneliness scale was constructed by Russell D (1996), The State-Trait Anger expression inventory-2 Psychological Assessment Resources(1999), Rosenberg self esteem scale Rosenberg (1965),The mental health inventory (MHI-38), Academic stress( Gadzella's (1994) students life stress inventory SLSI) Childhood behaviour (ACE score (1999)) Gulit and Shame Taya R.Cohen (2011) were used to collect data. Results were statistically analyzed through't' test, correlation coefficient. In this present research it has been concluded gender has an influences on mental health and its factors such as Family factor, Loneliness, State and Trait Anger, Self esteem, Academic stress, Childhood behaviour, Guilt and Shame.
\end{abstract}

Keywords: Family factor, Loneliness, State and Trait Anger, Self esteem, Mental health, Academic stress, Childhood behaviour, Guilt and Shame

\section{Introduction}

Mental health is an important part of the student's educational experiences. Poor mental health can affect academic achievement, student relation and family relation. As more students seek counselling, mental health issues are fast becoming a new focus of higher education (Kitzrow, 2003). Schools are beginning to pay more attention to mental health and counselling issues among students. On the part of counsellors and administrators, there is a greater understanding of student's development and desire to avoid legal consequences that can occur if the mental health of students is not addressed (Cooper, 2000). Anger and stress in students are increasingly important topics to today's educators and school professionals are confronted not only with the direct effects of anger and stress, such as threats of violence and fighting among students, but also with the indirect effects that appear in the form of learning difficulties affect mental health and social adjustment problems. This is aims to take a comprehensive look at the problems associated with the anger and stress on their mental health in today's student and at development of the student is the ultimate goal of education and therefore the learning experience provided to them contribute towards the achievement of this end. Right from the birth, the student is influenced by all the factors surrounding him though individual differences due to family factor, loneliness, state and trait anger, self esteem, mental health, academic stress, childhood behaviour guilt and shame. Mental health is gendered. One of the most consistent findings in the study of mental health is that women have higher rates of anger, stress and psychological treatment than men do (Anesthensel 1992, Caldwell, Pearson, and Chin 1987, Dohrewend and Dohrewend 1974, 1976, Gove 1972, 19887, Mirowsky and Ross 1986, Rosenfield 1989). The association between gender and mental health therefore has become a prominent topic not only in sociology but also in the fields of psychology, epidemiology, and public health. Sociologists have produced abundant empirical studies concerning gender impact on mental health and its psychological factors status and their social determinants. Nevertheless the literature lacks a synthesis of major findings and a reflection on the current development of this area. This paper aims to fill these gaps.

\section{Related Work}

Mental health is not just the absence of the mental illness. It is defined as a state of well-being in which every individual realises his or her own potential, can cope with the normal stresses of life, can work productively and fruitfully, and is able to make a contribution to his or her community. (WHO, 2007) Mental health is an important part of student's educational experiences. Poor mental health can affect academic achievement, student retention, and graduation rates. As more students seek counselling, mental health issues are fast becoming a new focus of higher education administrators (Kitzrow, 2003). The students are beginning to pay more attention to mental health and counselling issues among students. On the part of counsellors and administrators, there is a greater understanding of young adult development and a desire to avoid legal consequences that can occur if the mental health of students is not addressed (Cooper, 2000). People in good mental health are better able to cope when things go wrong; feeling stressed makes it harder for us to cope with problems. The mental health is explained as activities performed to help individuals suffering from problems to save them and guide people on prevention of problems and confusion. Thus the mental health never neglects quality of human physical health. There are three critical components of health: Physical, mental and social. It can be said that mental health means creating a balance between the environments, human needs and desires that always trickle events and stress cause the equilibrium to be put at risk. Because of this reason physical and mental health are related together and as we educate and promote awareness of various physical ailments prevented, in the first 


\section{International Journal of Science and Research (IJSR) \\ ISSN (Online): 2319-7064}

Index Copernicus Value (2013): 6.14 | Impact Factor (2014): 5.611

principle of mental health our goal is prevention (Divine, 1388). Some people are more prone to anger and various social and psychological factors affect the formation of expressing anger (Bvshmn \&Bamystr 1998). Anger negatively affects physical and mental health, social interaction and quality of life (Dahln \&diphenhydramine, 2001). Anger may lead to family, Interpersonal, job conflicts, negative evaluation of others and low self-esteem (Marie merchandise \& pin, 2003). Regarding the negative effects of social and individual anger, control of anger is important. Anger management and control interventions, reduce the emotional feelings and the physiological arousal of anger, Increase awareness and education about anger practices and effective strategies to control it (Psychological Society of America, 2004). Anger management skills, including: Social protection systems skills, listening skills, Probable links between and negotiation skills, problem solving skills, relaxation skills, expertise and skills to maintain internal controls of humor. Anger management is effective in increasing mental health group. Lack of anger control training is effective to control the increasing mental health. The Anger control training on mental health impacts (Hojatallah Tahmasebian, et al. 2014). Stress can have positive and negative effects on a child. Some stress for everyone is normal and healthy; it keeps us alert and aware of the things that are happening around us. However, excessive stress can be quite harmful to a child. Research has shown that the negative effects of stress on children under the age of 10 are far more profound and longer lasting (Jewett \& Peterson, 2003). Dealing with stress is dependent on a child's development level as well as their development of copingskills at that age (Jewett\& Peterson). Children that are exposed to long term stressors and continued use of unhealthy coping strategies can result in behaviour patterns that may be difficult to change, due to the fact that the child begins to see these strategies as being effective (K0chenderfer-Ladd\& Skinner,2002). Kassinove (1995) put forward an interesting statistics about the number of studies carried out in past 25 years on anger, aggression and anxiety, in that order, indicating that anger has been relatively ignored in the past. Spielbeger et al. (1970) formulated definitions of state-anger and trait-anger. He defined state-anger as -a psychological state consisting of subjective feelings that vary in intensity from mild irritation to intense fury and would fluctuate over time as a function of frustration, perceived insults or being verbally or physically attacked", while traitanger was defined in term of how often angry feelings were experienced over time by a person. Wilde (2014) cited Murray's (1985) findings that showed subjects who are given an opportunity to express anger after they have been criticized often makes the subjects angrier. This finding is pertinent to this study since several of the scales and subscales of STAXT-2 (Spielberger, 1999) are concerned with anger expression and/or anger control. In the light of this context the present study is entitled as Gender impact on mental health and its psychological factor" for the present research has been taken up. The focus for this study is on higher secondary school students. A stratified random Sampling technique that was used for the selection of the sample in this case was random sampling technique. A total of 50 school students were selected from three different schools in Chennai city. The investigator selected 25 students from Government from 15 students from Government aided school and 10 students from private school.

\section{Sample}

The investigator selected 25 students from government school, 15 students from Government Aided School and 10 students from Private school.

\section{Objectives of the Study}

To know the impact of gender on mental health and its psychological factors.

\section{Hypotheses of the Study}

1) There are no significant differences between the family factor boys and girls from the total sample.

2) There are no significant differences between the loneliness boys and girls from the total sample.

3) There are no significant differences between the state anger boys and girls from the total sample.

4) There are no significant differences between the trait anger boys and girls from the total sample.

5) There are no significant differences between the self esteem boys and girls from the total sample.

6) There are no significant differences between the mental health boys and girls from the total sample.

7) There are no significant differences between the academic stress boys and girls from the total sample.

8) There are no significant differences between the childhood behaviour boys and girls from the total sample.

9) There are no significant differences between the guilt boys and girls from the total sample.

10) There are no significant differences between the shame boys and girls from the total sample.

\section{Research Tools Selected for the Present Study}

The following tools have been used by the investigator to carry out this study.

1) Personal data sheet developed by the investigator.

2) Family factor scale prepared and valid by Dr. (Mrs.).K. Saraladevi, and Dr. (Mrs.) Angela Selvarani (2006)

3) Loneliness scale was constructed by Russell D (1996)

4) The State-Trait Anger expression Inventory-2 (Psychological assessment Resources, 1999)

5) Rosenberg self esteem scale (Rosenberg 1965)

6) The Mental health Inventory (MHI-38)

7) Academic stress ( Gadzell's (1994) students life stress inventory SLSI)

8) Guilt and Shame Taya R.Cohen (Carnegie Mellon University)

\section{Hypothesis: 1}

Table1: Differentiation family factors between boys and girls

\begin{tabular}{|c|c|c|c|c|c|c|}
\hline Variable & Gender & N & Mean & S.D & C.R & L.S \\
\hline $\begin{array}{c}\text { Family } \\
\text { factor }\end{array}$ & Boys & 25 & 168.88 & 14.7998 & 3.7857 & 0.001 \\
\cline { 2 - 5 } & Girls & 25 & 153.24 & 14.41 & & \\
\hline
\end{tabular}

\section{Volume 4 Issue 11, November 2015}




\section{International Journal of Science and Research (IJSR) \\ ISSN (Online): 2319-7064}

Index Copernicus Value (2013): 6.14 $\mid$ Impact Factor (2014): 5.611

${ }^{*} \mathrm{p}<0.05, * * \mathrm{p}<0.01, * * * \mathrm{p}<0.001$

\section{Hypothesis: 2}

Table 2: Differentiation of loneliness between boys and girls

\begin{tabular}{|c|c|c|c|c|c|c|}
\hline Variable & Gender & $\mathrm{N}$ & Mean & S.D & C.R & L.S \\
\hline loneliness & Boys & 25 & 36.2 & 2.84 & 18.9685 & 0.001 \\
\cline { 2 - 5 } & Girls & 25 & 48.08 & 1.319 & & \\
\hline & $* 0.05, * * p<0.01, * * * p<0.001$ \\
\hline
\end{tabular}

\section{Hypothesis: 3}

Table 3: Differentiation of state anger between boys and girls

\begin{tabular}{c|c|c|c|c|c|c|c|}
\hline Variable & Gender & $N$ & Mean & S.D & C.R & L.S \\
\hline \multirow{2}{*}{$\begin{array}{c}\text { State } \\
\text { anger }\end{array}$} & Boys & 25 & 35.480 & 2.627 & 7.3132 & 0.001 \\
\cline { 2 - 5 } & Girls & 25 & 28.652 & 3.8590 & & \\
\hline
\end{tabular}

\section{Hypothesis: 4}

Table 4: Differentiation of trait anger between boys and girls

\begin{tabular}{|c|c|c|c|c|c|c|}
\hline Variable & Gender & $N$ & Mean & S.D & C.R & L.S \\
\hline \multirow{2}{*}{$\begin{array}{c}\text { Trait } \\
\text { anger }\end{array}$} & Boys & 25 & 34.360 & 3.3921 & 13.0293 & 0.001 \\
\cline { 2 - 5 } & Girls & 25 & 20.760 & 3.8193 & & \\
\hline
\end{tabular}

$*_{\mathrm{p}}<0.05, * * \mathrm{p}<0.01, * * * \mathrm{p}<0.001$

\section{Hypothesis: 5}

Table 5: Differentiation self esteem between boys and girls.

\begin{tabular}{|c|l|c|c|c|c|c|}
\hline Variable & Gender & $N$ & Mean & S.D & C.R & L.S \\
\hline Self esteem & Boys & 25 & 32.320 & 2.5 & 10.4329 & 0.001 \\
\cline { 2 - 5 } & Girls & 25 & 26.440 & 2.8 & & \\
\hline
\end{tabular}

\section{Hypothesis: 6}

Table 6: Differentiation mental health between boys and girls

\begin{tabular}{c}
\begin{tabular}{|c|c|c|c|c|c|c|}
\hline Variable & Gender & $N$ & Mean & S.D & C.R & L.S \\
\hline $\begin{array}{c}\text { Mental } \\
\text { health }\end{array}$ & Boys & 25 & 185.4 & 9.716 & 23.4042 & 0.001 \\
\cline { 2 - 4 } & Girls & 25 & 26.440 & 4.5 & & \\
\hline
\end{tabular} \\
* $<0.05, * * \mathrm{p}<0.01, * * * \mathrm{p}<0.001$ \\
\hline
\end{tabular}

\section{Hypothesis: 7}

Table 7: Differentiation of academic stress between boys and girls

\begin{tabular}{|c|c|c|c|c|c|c|}
\hline Variable & Gender & $N$ & Mean & S.D & C.R & L.S \\
\hline $\begin{array}{c}\text { Academic } \\
\text { stress }\end{array}$ & Boys & 25 & 69.320 & 5.0960 & 11.1918 & 0.001 \\
\cline { 2 - 5 } & Girls & 25 & 50.44 & 6.7213 & & \\
\hline
\end{tabular}

\section{Hypothesis: 8}

Table 8: Differentiation of childhood behaviour between boys and girls

\begin{tabular}{|c|c|c|c|c|c|c|}
\hline Variable & Gender & $N$ & Mean & S.D & C.R & L.S \\
\hline $\begin{array}{c}\text { Childhood } \\
\text { behaviour }\end{array}$ & Boys & 25 & 5.960 & 0.9069 & 5.0553 & 0.001 \\
\cline { 2 - 6 } & Girls & 25 & 5.640 & 0.8718 & & \\
\hline $\mathrm{p}<0.05, * * \mathrm{p}<0.01, * * * \mathrm{p}<0.001$
\end{tabular}

\section{Hypothesis: 9}

Table 9: Differentiation of guilt between boys and girls

\begin{tabular}{|c|c|c|c|c|l|l|}
\hline Variable & Gender & $N$ & Mean & S.D & C.R & L.S \\
\hline \multirow{2}{*}{ Guilt } & Boys & 25 & 30.720 & 4.7034 & 25.2453 & 0.001 \\
\cline { 2 - 5 } & Girls & 25 & 61.20 & 3.7842 & & \\
\hline
\end{tabular}

Table 10: Differentiation of shame between boys and girls

\begin{tabular}{|c|l|l|l|l|l|l|}
\hline Variable & Gender & $N$ & Mean & S.D & C.R & L.S \\
\hline \multirow{2}{*}{ Shame } & Boys & 25 & 33.28 & 4.0676 & 2.4798 & 0.05 \\
\cline { 2 - 5 } & Girls & 25 & 30.76 & 3.0447 & & \\
\hline
\end{tabular}

From the table 1 , it is observed that the obtained $\mathrm{t}^{\mathrm{t}}$ value $(p<0.001)$ is greater than the table value $(3.090)$ at 0.001 level of significance. Hence it is inferred that there is significant difference between boys and girls among family factors. Hence hypothesis rejected.

The study was designed to investigate the effect of gender on Family factors (parent character, parent attitude, Father Attitude, parental encouragement, parent love) and Life factors (quality of life, satisfaction with life and meaning in life). Sample consists of 900 Higher Secondary School students. Tools chosen for the study were Family factors scale by K.Saraladevi and Angela Selvarani (2011), satisfaction with life by ED Deiner et al (1985) quality of life and meaning in life by Micheael.F.Stegar et al (2014). Means of the variables were recorded. Statistical analyses were done on the different variable scores. It was found that gender has an impact on family factors and life factors. (Souda Nalina Kumari, Dr. K. Saraladevi 2015 Gender Impact on Family Factors and Life Factors" International Journal of Informative \& Futuristic Research (IJIFR) Volume - 2, Issue - 11, July 2015 23rdEdition, Page No: 4044-4052).

From the table 2 , it is observed that the obtained ' $t$ ' value $(p<0.001)$ is greater than the table value $(3.090)$ at 0.001 level of significance. Hence it is inferred that there is significant difference between boys and girls among loneliness. Hence hypothesis rejected.

The goal of this study is to determine the relationship between loneliness and social acceptance and the academic performance of the students. The research is descriptivecorrelative and the statistical population is Lar's high school students of the school year of 2011-2012. Using multistage random sampling method, 342 students (180 girls and 162 boys) were selected as the statistical sample. Loneliness Questionnaire by Asher, Hymel and Renshaw and also the Marlowe-Crowne Social Desirability Scale were used to collect the data. Pearson correlation coefficient showed that loneliness has a significant relationship with the academic progress of the students $(\mathrm{p}<0.001)$. Nevertheless, there is no significant relationship between social acceptance and academic progress. The analysis of multivariate regression showed that loneliness is the most powerful variable in the prediction of academic achievement. The results also showed that there is no significant relationship between boy and girl students regarding social acceptance. Nonetheless, the academic progress $(p<0.05)$ and loneliness $(p<0.01)$ are

\section{Volume 4 Issue 11, November 2015}




\section{International Journal of Science and Research (IJSR) \\ ISSN (Online): 2319-7064}

Index Copernicus Value (2013): 6.14 | Impact Factor (2014): 5.611

higher in girls compared to boys. (Eghbalzarei et al., 2011 The relationship between Loneliness and social acceptance and the academic performance Journal of life science and biomedicine. Vol 3 iss 2 pg: 171-175).

From the table 3 , it is observed that the obtained ' $t$ ' value $(p<0.001)$ is greater than the tabled value (3.090) at 0.001 level of significance. Hence it is inferred that there is significant difference between boys and girls among state anger. Hence hypothesis rejected.

The manner in which women express and experience their anger has been a topic of interest for decades. In the popular press, women have been instructed to express their anger in a variety of ways: ignore it, appropriately manage it, protect their husbands from it, and/or voice it (Cancian \& Gordon, 1988). More recently, the study of women and anger has been undertaken by professional researchers and theoreticians (e.g., Lemer, 1985; Kopper \& Epperson, 1991; Biaggio, 1989; Thomas, 1989). These and other authors have hypothesized that women's expression and experience of anger is affected in significant ways by cultural mores regarding anger. For instance, traditional socialization and taboos against women expressing anger have led to a culture where women are rewarded for hiding their anger, or for expressing it indirectly. However, current theoretical work indicates that suppression or indirect expression of anger may lead to a variety of mental health problems such as depression, guilt, and unhealthy relationships. (Susan Renee stock-ward 1995 women's anger: the roles of gender, sex role, and feminist identity in women's anger expression and experience". Retrospective theses and Dissertation paper 11089)

From the table 4 , it is observed that the obtained ' $t$ ' value $(p<0.001)$ is greater than the table value $(3.090)$ at 0.001 level of significance. Hence it is inferred that there is significant difference between boys and girls among trait anger. Hence hypothesis rejected.

Anger is a response to the perception of threat, conflict, injustice, negligence, humiliation, or betrayal. It may be expressed actively as well as passively. Anger can be suppressed, and then converted or redirected. It happens When one hold in anger, stop thinking about anger, and focus on something positive. Anger turned may cause hypertension, high blood pressure, or depression. This study explores the gender differences in anger expression among 320 persons (160 male and 160 female) between the age ranges of 14 to 52 years with a mean age of 33.5 years. The participants were assessed with STAXI-2 (Hindi version). The obtained data was analyzed using t-test. There were significant gender differences in various systems of anger expression. The significant gender differences in anger expression further implies that anger management strategies should be gender specific. (Mamta and Nov Rattan Sharma 2013 Across gender comparison in anger expression". Global international Research thoughts (GIRT) ISSN 2347-886 pg: 1-9)

From the table 5 , it is observed that the obtained ' $t$ ' value $(p<0.001)$ is greater than the table value $(3.090)$ at 0.001 level of significance. Hence it is inferred that there is significant difference between boys and girls among self esteem. Hence hypothesis rejected.

A longitudinal study of a general population $(n=219$; M age: 12, 13 and 14), was carried out between 1990 and 1993 over 3 years in Lausanne (Switzerland). Several questionnaires, validated in French, were used: Perceived Competence Scale, Social Support Appraisal and a questionnaire on mental health developed in our research Unit. We attempted to answer the following questions: Is there a global change in self-esteem during early adolescence? If so, does the way in which the young person perceives himself vary according to the social and relational environment? What are the differences between boys and girls in the development of self-esteem? What is the relation between self-esteem and mental health? As to the specific differences according to gender, results show that girls tend to have a poorer selfesteem than boys, whatever the domains taken into consideration. Differences are more significant with reference to appearance and athletic performance. As far as the development of self-esteem is concerned, there is no major change, notably when considering global perception. Results of a factor analysis underscore the fact that girls' selfesteem is more global and less differentiated by domain while boys separate the scholastic and behavioural part of their experience from the social. Global self-esteem has more influence on the level of depressive mood in girls than in boys. (M.Bolognini and B. Plancherel. 1996 Self esteem and mental health in early adolescence: development and gender differences" J Adolesc, vol 19(3):233-245.)

From the table 6 , it is observed that the obtained ${ }^{6} t^{\mathrm{t}}$ value $(p<0.001)$ is greater than the table value $(3.090)$ at 0.001 level of significance. Hence it is inferred that there is significant difference between boys and girls among mental health. Hence hypothesis rejected.

We examined gender differences in mental health outcomes during and post-recession versus pre-recession. We utilized 2005-2006, 2008-2009, and 2010-2011 data from the Medical Expenditure Panel Survey. Females had lower odds of depression diagnoses during and post-recession and better mental health during the recession, but higher odds of anxiety diagnoses post-recession. Males had lower odds of depression diagnoses and better mental health during and post-recession and lower Kessler 6 scores post-recession. We conducted stratified analyses, which confirmed that the aforementioned findings were consistent across the four different regions of the U.S., by employment status, income and health care utilization. Importantly, we found that the higher odds of anxiety diagnoses among females after the recession were mainly prominent among specific subgroups of females: those who lived in the Northeast or the Midwest, the unemployed, and those with low household income. Gender differences in mental health in association with the economic recession highlight the importance of policymakers taking these differences into consideration when designing economic and social policies to address economic downturns. Future research should examine the reasons behind the decreased depression diagnoses among both genders, and whether they signify decreased mental healthcare utilization or increased social support and more time for exercise and 


\section{International Journal of Science and Research (IJSR) \\ ISSN (Online): 2319-7064}

Index Copernicus Value (2013): 6.14 | Impact Factor (2014): 5.611

leisure activities. (Rada K. Dagher ,Jie Chen, Stephen B. Gender Differences in Mental Health Outcomes before, during, and after the Great Recession" PLOS-ONE DOI: 10.1371/journal.pone.0124103)

From the table 7 , it is observed that the obtained ' $t$ ' value $(p<0.001)$ is greater than the table value $(3.090)$ at 0.001 level of significance. Hence it is inferred that there is significant difference between boys and girls among academic stress. Hence hypothesis rejected.

The purpose of the present study was to reduce the Academic Stress of higher secondary students and find out the differences if any in terms of Gender, Type of Family, Type of School Management, Family Income and Stream of Study. The samples for the study comprised of 250 higher secondary school students in Thiruvannamalai District. Survey method was adopted and simple random sampling technique was used to carry out the present research. The investigator has used descriptive and differential statistical methods for analysing the collected data. It was found that there is significant difference in the Academic Stress of higher secondary students in relation to their Gender, Type of Family, Type of School Management and further there is no significant difference in the Academic Stress of higher secondary students in relation to their Family Income and Stream of Study. The findings could be useful for the students to know their level of stress and they can take up necessary and sufficient practices to reduce their Academic Stress. (S. Menaga, Full-time Ph.D. Research Scholar and V. Chandrasekaran, Ph.D. 2014 SRJIS vol 2/XIV pg: 19731981).

From the table 8 , it is observed that the obtained ' $t$ ' value $(p<0.001)$ is greater than the table value $(3.090)$ at 0.001 level of significance. Hence it is inferred that there is significant difference between boys and girls childhood behaviour. Hence hypothesis rejected. Testosterone plays an important role in mammalian brain development. In neural regions with appropriate receptors testosterone, or its metabolites, influences patterns of cell death and survival, neural connectivity and neurochemical characterization. Consequently, testosterone exposure during critical periods of early development produces permanent behavioural changes. In humans, affected behaviours include childhood play behaviour, sexual orientation, core gender identity and other characteristics that show sex differences (i.e. differ on average between males and females). These influences have been demonstrated primarily in individuals who experienced marked prenatal hormone abnormalities and associated ambiguities of genital development (e.g. congenital adrenal hyperplasia). However, there is also evidence that testosterone works within the normal range to make some individuals within each sex more sex-typical than others. The size of testosterone-related influences, and perhaps even their existence, varies from one sex-typed characteristic to another. For instance: prenatal exposure to high levels of testosterone has a substantial influence on sex-typical play behaviour, including sex-typed toy preferences, whereas influences on core gender identify and sexual orientation are less dramatic. In addition: there appears to be little or no influence of prenatal testosterone on mental rotations ability, although mental rotations ability shows a marked sex difference. These findings have implications for basic understanding of the role of testosterone in normative gender development, as well as for the clinical management of individuals with disorders of sex development (formerly called intersex syndromes). (Melissa Hines 2006 Prenatal testosterone and gender-related behaviour" European Journal of Endocrinology 155 S115-S121 ISSN 0804-4643).

From the table 9, it is observed that the obtained ' $t$ ' value $(p<0.001)$ is greater than the table value $(3.090)$ at 0.001 level of significance. Hence it is inferred that there is significant difference between boys and girls among guilt. Hence hypothesis rejected. This article examines the relationship among gender, guilt, shame, empathy and blaming among an incarcerated sample of male and female offenders who completed a correction-based Impact of Crime on Victims course (ICVC). A sample of 124 respondents (97 females and 27 males) completed pre- and post-test questionnaires assessing guilt, shame, empathy, victim- and society-blaming. Results overall indicate no significant gender differences among offenders'. Findings do indicate significant differences among violent and non-violent offenders on levels of shame and blaming and suggest that although gender-specific programs that address female issues are necessary, programs that address both criminogenic and non-criminogenic are needed. (Jackson, Blackburn, Tobolowsky, Baer-An Examination of Guilt, Shame, Empathy and Blaming Among a Sample of Incarcerated Male and Female Offenders (2011) Southwest Journal of Criminal Justice, Vol. 8(1). pp. 4-29. (C) 2011 Southwestern Association of Criminal Justice).

From the table 10 , it is observed that the obtained ${ }^{\prime} t^{6}$ value $(p<0.05)$ is greater than the table value $(1.96)$ at 0.05 level of significance. Hence it is inferred that there is significant difference between boys and girls among shame. Hence hypothesis rejected. The purpose of this study was to examine the effects of gender and culture on shame-focused attitudes toward mental health problems. Two hundred and ninety-three university students from Asian, Latino, and Caucasian American cultural backgrounds participated in the study. The Attitudes toward Mental Health Problems Scale was used to measure shame-focused attitudes. A 2 (gender) $\times$ 3 (culture) multivariate analyses of variance was performed. Results indicated that there was no significant gender difference in shame-focused attitudes toward mental health problems. Of the three ethnic cultural groups, Latino American students had the highest mean score on how shameful they would feel if they had mental health problems. Asian American students had the lowest mean score on how negative their families would view themselves if they had mental health problems. Implications of the results for rehabilitation research and practice are discussed. (Jessica Benetti-McQuoid1 and Krisanne Bursik 2005 Individual Differences in Experiences of and Responses to Guilt and Shame: Examining the Lenses of Gender and Gender Role" Sex Roles, Vol. 53, Nos. 1/2, Pg: 133 -142.) 


\section{International Journal of Science and Research (IJSR) \\ ISSN (Online): 2319-7064}

Index Copernicus Value (2013): 6.14 | Impact Factor (2014): 5.611

\section{Discussion}

Gender differences found in higher secondary students are in part a product of an individual's family factor during childhood. The present study we found that family factor has reveals that males are more influence of the factor on mental health than females as concluded by Lowe et al., 2014

\section{Educational Implications}

- The American College Health Association survey finds strong evidence that mental health needs are related to measures of academic success. The survey found that student who reported psychological distress also reporting receiving a lower grade on an exam or an important project; receiving a lower grade in the course; receiving an incomplete or dropping the course. Students with high levels of psychological stress are less academically successful they have more test on anger and stress and less effective time management and use of study resources.

- Students with higher levels of mental health impact then they have more difficulty concentrating on their schoolwork; they are less likely to persist when faced with distraction or difficulty. (Brackney and Karabenick 1995).

- The students who experience mild or moderate impact fact of mental health also demonstrate more academic difficulties and lower level grade then non-experience students (Locke, 2009; Deroma, Leach, and Leverett, 2009)

\section{Delimitations}

1) The sample is restricted to higher secondary school students from Chennai district

2) The sample size is restricted to 50 students only.

\section{Conclusion}

Gender has impact on student's mental health among higher secondary school students. There are significant differences in the levels of the psychological factors such as family factor, state and trait anger, loneliness, self-esteem, mental health, academic stress, guilt and shame of boys and girls in the total sample.

\section{References}

[1] Souda Nalina Kumari, Dr. K. Saraladevi 2015 Gender Impact on Family Factors and Life Factors" International Journal of Informative \& Futuristic Research (IJIFR) Volume - 2, Issue - 11, July 2015 23rdEdition, Page No: 4044-4052).

[2] Eghbalzarei et al., 2011 The relationship between Loneliness and social acceptance and the academic performance Journal of life science and biomedicine. Vol 3 iss 2 pg: 171-175).

[3] Susan Renee stock-ward 1995 women's anger: the roles of gender, sex role, and feminist identity in women's anger expression and experience". Retrospective theses and Dissertation paper 11089
[4] Mamta and Nov Rattan Sharma 2013 Across gender comparison in anger expression". Global international Research thoughts (GIRT) ISSN 2347-886 pg: 1-9

[5] M.Bolognini and B. Plancherel. 1996 Self esteem and mental health in early adolescence: development and gender differences" J Adolesc, vol 19(3):233-245.

[6] Rada K. Dagher ,Jie Chen, Stephen B. Gender Differences in Mental Health Outcomes before, during, and after the Great Recession" PLOS-ONE DOI: 10.1371/journal.pone.0124103

[7] S. Menaga, Full-time Ph.D. Research Scholar and V. Chandrasekaran, Ph.D. 2014 SRJIS vol 2/XIV pg: 19731981

[8] Jackson, Blackburn, Tobolowsky, Baer-An Examination of Guilt, Shame, Empathy and Blaming Among a Sample of Incarcerated Male and Female Offenders (2011) Southwest Journal of Criminal Justice, Vol. 8(1). pp. 4-29. (C) 2011 Southwestern Association of Criminal Justice

[9] Jackson, Blackburn, Tobolowsky, Baer-An Examination of Guilt, Shame, Empathy and Blaming Among a Sample of Incarcerated Male and Female Offenders (2011) Southwest Journal of Criminal Justice, Vol. 8(1). pp. 4-29. (C) 2011 Southwestern Association of Criminal Justice

[10] Jessica Benetti-McQuoid1 and Krisanne Bursik 2005 Individual Differences in Experiences of and Responses to Guilt and Shame: Examining the Lenses of Gender and Gender Role” Sex Roles, Vol. 53, Nos. 1/2, Pg: 133 -142 .

[11].Derdikman-Eiron, R.et al., Gender differences in subjective well-being, self-esteem and psychosocial functioning in adolescents with symptoms of anxiety and depression". Scandinavian Journal of Psychology, 52(3),261-7,(2011).

[12] Champika K. Soysa \& Carolyn J. Wilcomb, Mindfulness, Self-compassion, Self-efficacy, and Gender as Predictors of Depression, Anxiety, Stress, and Well-being". Springer Science, (2013). 